\title{
An Experimental Study on Solidifying Municipal Sewage Sludge through Skeleton Building Using Cement and Coal Gangue
}

\author{
Jiankang Yang, ${ }^{1}$ Haijun Lu, ${ }^{1}$ Xiong Zhang, ${ }^{2}$ Jixiang Li, ${ }^{1}$ and Weiwei Wang ${ }^{1}$ \\ ${ }^{1}$ Institute of Poromechanics, Wuhan Polytechnic University, Wuhan 430023, China \\ ${ }^{2}$ Department of Civil, Architectural, and Environmental Engineering, Missouri University of Science and Technology, Rolla, MO, USA \\ Correspondence should be addressed to Haijun Lu; lhj_whpu@163.com
}

Received 31 August 2016; Revised 24 December 2016; Accepted 23 January 2017; Published 16 February 2017

Academic Editor: Charles C. Sorrell

Copyright (c) 2017 Jiankang Yang et al. This is an open access article distributed under the Creative Commons Attribution License, which permits unrestricted use, distribution, and reproduction in any medium, provided the original work is properly cited.

\begin{abstract}
The municipal sewage sludge typically has very high water content and low shear strength. Conventional methods of lime and cement solidification of municipal sewage sludge often suffer high cost, significant drying shrinkage, frequent cracking, high hydraulic conductivity, and low strength. To overcome these shortcomings, in this paper a skeleton-building method was used to solidify municipal sewage sludge in which coal gangue, cement and clay, and fiber were used as skeleton materials, cementation materials, and filling materials, respectively. Comprehensive laboratory tests including cracking, nitrogen adsorption, triaxial shearing, and permeability tests were performed to determine cracking, pore structure, shear strength, and hydraulic conductivity of municipal sewage sludge solidified with different proportions of coal gangue, cement, fiber, and clay. Based upon the experimental results, the mechanisms of the skeleton building using cement and coal gangue were discussed and factors controlling the mechanical and hydraulic behavior of the solidified soils were analyzed at both microscopic and macroscopic levels. Based upon the test results and analyses, recommendations were made for solidifying municipal sewage sludge through skeleton building using cement and coal gangue. The solidified soils have high soil strength, high resistance to cracking, and low hydraulic conductivity which are sufficient for being used as landfill liner.
\end{abstract}

\section{Introduction}

The amount of both municipal and industrial solid waste has significantly increased with the rapid urbanization in China. Among these wastes, municipal sludge and coal gangue are typical. The quantity of wastewater discharge has reached $440 \times 10^{8} \mathrm{~m}^{3} /$ day in 2010 and is expected to reach $536 \times$ $10^{8} \mathrm{~m}^{3} /$ day till 2020 . Wastewater often contains $0.3 \%-0.5 \%$ sewage sludge. The total amount of coal gangue produced around the world is more than $50 \times 10^{8}$ ton per year. In China only the total volume of disposed coal gangue is $20 \times$ $10^{8}$ ton per year, which occupies more than 6,670 ha of land. Municipal sewage sludge consists of high contents of water and organic matter, which lead to very low soil strength. In the meantime, coal gangue contains plenty of inorganic salts, low moisture content, and high shear strength. Both materials contain certain amount of heavy metal substance, which can result in contamination to the environment and occupation of agricultural land if not properly handled.

Land disposal has been the most commonly used method to treat municipal sludge and coal gangue. Although landfills can accept a variety of waste that could contain a mixture of organic and inorganic hazardous constituents, poorly constructed landfills and migration of leachate from landfills pose a serious threat to the environment and public safety. Due to its extremely high water content and low strength, to ensure landfill stability, the sludge should be solidified or stabilized before disposal. Cement, lime, and clay are traditional materials used to solidify sludge $[1,2]$. However, the cost for the solidification are often prohibitively high and the treated sludge after solidification/stabilization (S/S) often exhibits significant drying shrinkage, frequent cracking, high hydraulic conductivity, and low strength. Many attempts have been made to solidify sewage sludge using burned ash of 
TABLE 1: Basic physical and chemical properties of sewage sludge.

\begin{tabular}{lccccc}
\hline $\begin{array}{l}\text { Moisture } \\
\text { content } \\
(\%)\end{array}$ & $\begin{array}{c}\text { Organic matter } \\
\text { content } \\
(\%)\end{array}$ & $\mathrm{pH}$ & $\begin{array}{c}\text { Density } \\
\left(10^{3} \mathrm{~kg} / \mathrm{m}^{3}\right)\end{array}$ & $\begin{array}{c}\text { Total } \\
\text { nitrogen } \\
(\mathrm{mg} / \mathrm{g})\end{array}$ & $\begin{array}{c}\text { Total } \\
\text { phosphorus } \\
(\mathrm{mg} / \mathrm{g})\end{array}$ \\
\hline 220 & 45 & 6.8 & 1.08 & 13.2 & $\begin{array}{c}\text { Ammonia } \\
\text { nitrogen } \\
(\mathrm{mg} / \mathrm{g})\end{array}$ \\
\hline
\end{tabular}

TABLE 2: Chemical composition of coal gangue, clay, and cement (\%).

\begin{tabular}{lccccccc}
\hline & $\mathrm{SiO}_{2}$ & $\mathrm{AL}_{2} \mathrm{O}_{3}$ & $\mathrm{CaO}$ & $\mathrm{MgO}$ & $\mathrm{Fe}_{2} \mathrm{O}_{3}$ & $\mathrm{~K}_{2} \mathrm{O}$ & $\mathrm{Na}_{2} \mathrm{O}$ \\
\hline Clay & 58.42 & 25.23 & 0.51 & 0.12 & 0.24 & 5.32 & 2.67 \\
Cement & 31.73 & 16.32 & 47.52 & 1.98 & 2.45 & 0 & 0 \\
Gangue & 45.49 & 14.36 & 3.01 & 0.56 & 6.41 & 0 & 0 \\
\hline
\end{tabular}

rubbish, slag, and coal ash [3,4], but all of them are not very successful with similar high cost and low strength as well as other similar issues.

To overcome these shortcomings, recently some researchers proposed use of cement and waste materials with large particle sizes such as lignite and seafood shell, to form soil skeleton to solidify sludge, in order to reduce drying shrinkage and cracking, and to improve soil strength. The proposed method is very attractive due to its advantage of using one waste material to solidify another waste material. Preliminary test results indicated that the proposed method was promising and the obtained improvement in soil properties was significant [5]. For example, Dong et al. [6] used shells of walnut to solidify municipal sludge and significantly reduced the moisture content of the treated sludge from $97.5 \%$ to $63.6 \%$. However, due to the limited availability of the material, the method cannot be extensively used. Lee et al. [7] used cement and shell from seafood waste as conditioner to treat sludge. It was found that powder of seafood shell can significantly reduce the hydraulic conductivity and moisture content of the treated sludge. Kim et al. [8] explored the feasibility of using steel converter slag and lime to build soils skeleton to improve the shear strength of solidified municipal sludge. Experimental results indicated that the solidified municipal sludge had high shear strength and low permeability. However, the cost for the treatment was still high and possible cracking during drying process was not evaluated. Thapa et al. [9] proposed use of lignite to build soil skeleton to improve the mechanical performance and the dewatering efficiency of solidified sludge. Although preliminary test results indicating that the skeleton-building method for municipal sludge solidification is a promising technique, there is still a lack of complete understanding of the mechanism of skeleton-building method as well as hydraulic and mechanical behavior as well as microstructure of consolidated sludge. Consequently there is a great need for research in this area.

In this study, the skeleton-building method was used to solidify municipal sewage sludge in which coal gangue was used as skeleton material and cement, clay, and fiber were used as cementation and filling materials. Comprehensive laboratory tests including cracking, nitrogen adsorption, triaxial shearing, and permeability tests were performed to determine cracking, pore structure, shear strength, and hydraulic conductivity of municipal sewage sludge solidified with different proportions of coal gangue, cement, fiber and clay. Based upon the experimental results, the mechanisms of the skeleton building using cement and coal gangue were discussed and factors controlling the mechanical and hydraulic behavior of the solidified soils were analyzed at both microscopic and macroscopic levels. Based upon the test results and analyses, recommendations were made for solidifying municipal sewage sludge through skeleton building using cement and coal gangue.

\section{Test Materials and Methods}

2.1. Test Materials. The sewage sludge used in this study was obtained from the Wuhan Hanxi sewage treatment plant. The physical and chemical characteristics of the sewage sludge are shown in Table 1. The coal gangue used in this study was obtained from the Fuxin Open-Pit Coal Mine of Liaoning Province, China. Before being used, the coal gangue was broken into particles with a diameter size ranging from 1.0 and $3.0 \mathrm{~mm}$ using a grinding mill. The clay used was obtained from a construction site near Changqing Huayuan in Wuhan, Hubei Province, China. The cement used in the study was 425 ordinary Portland cement produced by Tanshang Jidong Cement Co., Ltd. (the compressive strength of the cement is $42.5 \mathrm{MPa}$ ). The chemical components of the coal gangue, clay, and cement are listed in Table 2. Table 3 shows the physical characteristics of the clay. The fiber used in the study was purchased from Wantai Engineering Material Co., Ltd. at Laiwu City of Shandong Province, China. Table 4 illustrates the basic physical characteristics of the fiber.

2.2. Experimental Design and Sample Preparation. As discussed previously, cement, coal gangue, clay, and fiber were used to solidify sewage sludge. The extensively used orthogonal design method was used to evaluate the effectiveness of the above-mentioned four different constituents on the performance of the solidified sewage sludge. A total of $9 \mathrm{mix}$ designs were used as shown in Table 5. For each constituent, three different levels of treatments were applied: for a test sample with a total mass of 1000 gram (column 2 in Table 5), 50,100 , and $150 \mathrm{~g} / \mathrm{kg}$ were used for cement addition, which is shown in the 3 rd column of Table 5 . For coal gangue, the three levels were 100, 150, and $200 \mathrm{~g} / \mathrm{kg}$ (column 4 in Table 5), while 
TABLE 3: Basic physical properties of clay.

\begin{tabular}{lcccccccc}
\hline$\rho_{d \max }$ & $W_{\text {opt }}$ & $W_{L}$ & $W_{p}$ & $I_{p}$ & \multicolumn{3}{c}{ Particle size distribution $(\%)$} \\
$(\mathrm{g} / \mathrm{cm} 3)$ & $(\%)$ & $(\%)$ & $(\%)$ & $(\%)$ & $>0.05 \mathrm{~mm}$ & $0.05 \sim 0.005 \mathrm{~mm}$ & $0.005 \sim 0.002 \mathrm{~mm}$ & $<0.002 \mathrm{~mm}$ \\
\hline 1.65 & 19 & 48.5 & 26.2 & 22.3 & 12 & 32 & 45 \\
\hline
\end{tabular}

TABLE 4: Basic physical properties of fiber.

\begin{tabular}{lcccc}
\hline $\begin{array}{l}\text { Length } \\
(\mathrm{mm})\end{array}$ & $\begin{array}{c}\text { Diameter } \\
(\mathrm{um})\end{array}$ & $\begin{array}{c}\text { Elastic } \\
\text { modulus } \\
(\mathrm{GPa})\end{array}$ & $\begin{array}{c}\text { Tensile } \\
\text { strength } \\
(\mathrm{MPa})\end{array}$ & $\begin{array}{c}\text { Elongation } \\
(\%)\end{array}$ \\
\hline 10 & $12 \sim 30$ & 3.5 & 350 & 30 \\
\hline
\end{tabular}

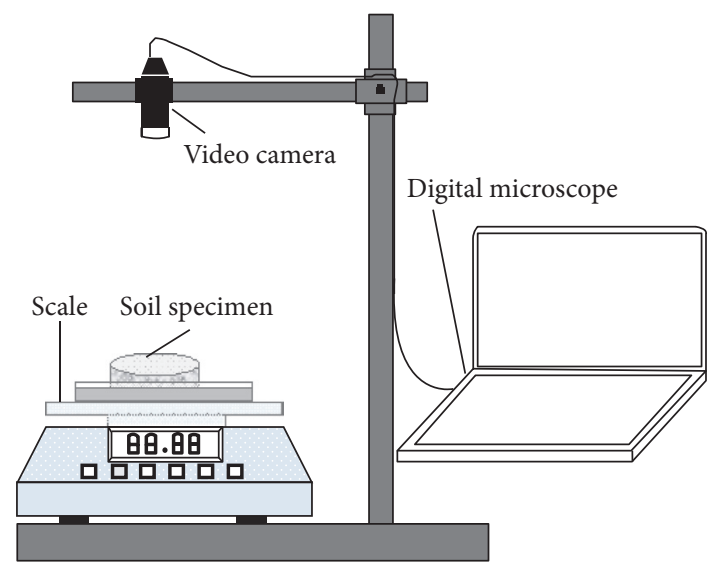

FIGURE 1: Setup of crack monitoring system.

for fiber and clay, the values were 1,2 , and $3 \mathrm{~g} / \mathrm{kg}$, and 0,50 , and $100 \mathrm{~g} / \mathrm{kg}$ (columns 5 and 6 in Table 5), respectively. The mass of the sewage sludge in each test sample is the difference between 1000 gram of total mass and the sum of the mass of the added constituents as shown in the 6th column of Table 5 .

For sample preparation, $2 \mathrm{~kg}$ sludge was first placed in the NJ-160 mixer and mixed at a rate of $60 \mathrm{r} /$ minute for 10 minutes to ensure the uniformity of the material. According to mix design as shown in Table 5, different masses of cement, coal gangue, clay, and fiber with different contents were added in proportion to the sewage sludge. After that, the mixture was mixed at a rate of $120 \mathrm{r} /$ minute for 20 minutes. The mixed materials were then transported to molds for curing.

For shrinkage and cracking tests, consolidation cutting rings were used, which have a diameter of $6.18 \mathrm{~cm}$ and a height of $2 \mathrm{~cm}$. During curing period, the specimen weight was measured using a digital balance from which moisture contents were determined. Surface cracks of samples were monitored using a digital microscope camera with a $\times 10$ magnification ratio (Figure 1). The cracking intensity factor (CIF), which is the ratio of the area of cracks to the total surface area of the solidified sample $[10,11]$, was used to quantify the surface cracking of samples. The color of the uncracked area was brighter than that of the cracked area. The differences in grayscale were used to calculate the CIF through a Digital Microscopy Image Analysis software.
A JW-BK static nitrogen adsorption instrument (Beijing JWGB Sci. \& Tech. Co., Ltd.) was used to measure the pore structure of samples during different curing stages. The instrument measured the static adsorption isotherms at the saturation temperature of liquid nitrogen. The relative pressure ranged from 0 to 0.99 . Twenty-two specific pressure points were used for the isothermal absorption, and another 22 specific pressure spots were applied for isothermal desorption to detect the specific area, pore diameter, and pore volume distribution of clay particles [12].

Triaxial tests were used to evaluate the shear strength of the solidified sludge. During the sample preparation, the soil mixture was first transported to a plastic cylinder of $10 \mathrm{~cm}$ in diameter and $18 \mathrm{~cm}$ in height and cured for at least 72 hours. After that the solidified sludge was taken out and then trimmed to samples with diameters and heights of samples 7 and $14 \mathrm{~cm}$, respectively, for consolidated-undrained triaxial shearing testing. The solidified sludge samples were tested to failure under three different confining pressures of 50, 100, and $150 \mathrm{kPa}$. The shear rate was controlled at a rate of $0.05 \%$ per minute. Failure was defined as the maximum volumetric and deviatoric strains of $5 \%$ and $15 \%$, respectively, whichever reached the first.

The flexible wall permeameter produced by GEOEQUIP Inc. was used to measure the hydraulic conductivity of the solidified sludge. The same plastic cylinder used for the triaxial shearing tests were used for same preparations. After being cured for at least 72 hours, the solidified sludge was taken out and then trimmed to soil samples with diameters and heights of samples $5 \mathrm{~cm}$ and $10 \mathrm{~cm}$, respectively, for the hydraulic conductivity tests. A confining pressure of $500 \mathrm{kPa}$ and back pressure of $300 \mathrm{kPa}$ were used to saturate the soils sample until the discharge pipe without bubbles was generated. Constant head permeability tests were performed. The outflow water was collected in a beaker every three hours. It was considered that seepage flow reached steady state until three consecutive measurements were identical. The hydraulic conductivity of the solidified sludge was then calculated accordingly.

\section{Results and Discussion}

3.1. Crack Development. Figure 2 shows the typical crack developments at different times for two solidified samples (Samples 6 and 9). Sample 6 experienced the most serious cracking as shown in Figure 2(a), while Sample 9 exhibited essentially no cracking as shown in Figure 2(b). As can be seen in Figure 2(a), after three days of drying, the solidified sewage sludge separated from the cutting ring due to drying shrinkage. Small cracks also appeared at the edge of the samples. The soil sample shrunk more after 7 days of drying, and the cracks grew from the edge to the center, although not 
TABLE 5: Relative amount of each constituent in the solidified sewage sludge (g).

\begin{tabular}{|c|c|c|c|c|c|c|}
\hline Sample & Total mass & Cement & Gangue & Fiber & Clay & Sludge \\
\hline 1 & 1000 & 50 & 100 & 1 & 0 & 849 \\
\hline 2 & 1000 & 50 & 150 & 2 & 50 & 748 \\
\hline 3 & 1000 & 50 & 200 & 3 & 100 & 647 \\
\hline 4 & 1000 & 100 & 100 & 2 & 100 & 698 \\
\hline 5 & 1000 & 100 & 150 & 3 & 0 & 747 \\
\hline 6 & 1000 & 100 & 200 & 1 & 50 & 649 \\
\hline 7 & 1000 & 150 & 100 & 3 & 50 & 697 \\
\hline 8 & 1000 & 150 & 150 & 1 & 100 & 599 \\
\hline 9 & 1000 & 150 & 200 & 2 & 0 & 648 \\
\hline
\end{tabular}

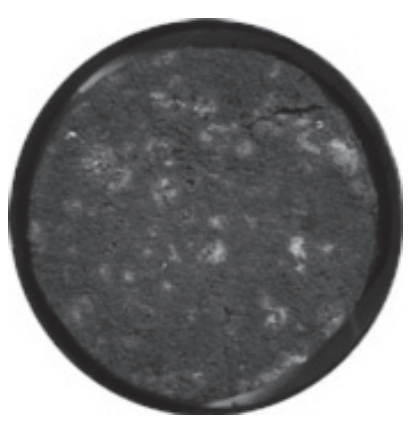

$3 d$

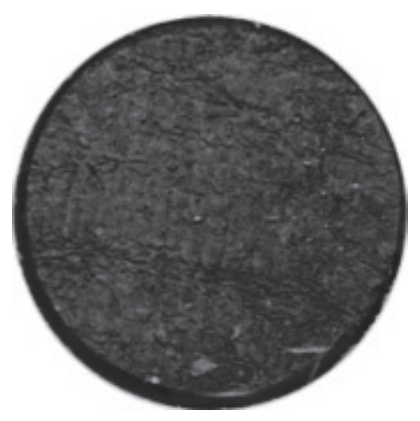

$3 \mathrm{~d}$

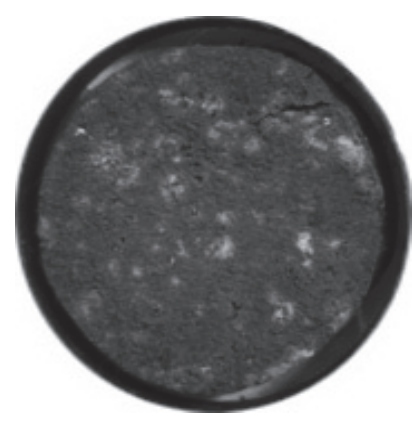

$7 \mathrm{~d}$

(a) Sample 6

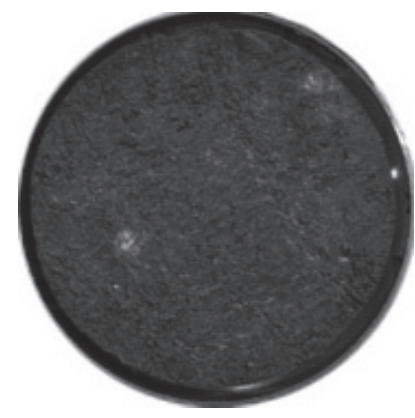

$7 d$

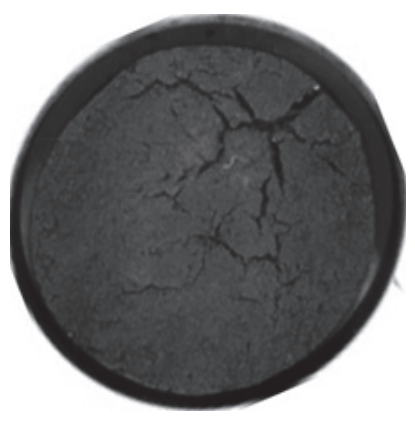

$28 \mathrm{~d}$

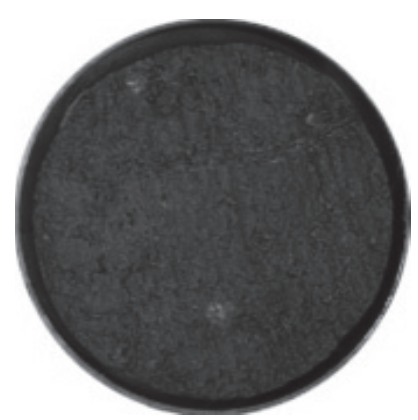

$28 \mathrm{~d}$

(b) Sample 9

Figure 2: Crack development with time for Samples 6 and 9.

very obvious. After 28 days of drying, a lot of cracks occurred with much larger widths and depths.

In contrast, Sample 9 exhibited essentially no cracks during the whole 28 days of drying process. The solidified soil sample did shrink to some degree, but with much smaller magnitude compared with Sample 6.

Figure 3 illustrates the variations of moisture content of 9 solidified sewage sludge samples with time during drying process. As can be seen from Figure 3, the moisture contents of all samples decreased quickly during the first 12 days and became stable after that. The initial moisture contents varied from $150.48 \%$ to $99.19 \%$. After 12 days, the moisture contents ranged from $48.28 \%$ to $24.03 \%$. Moisture contents of all samples finally stabilized at $21.16 \%-24.21 \%$ on the 28 th day of the drying period. Among the samples, the moisture content of Sample 1 was constantly the largest. It was also the one which had the quickest reduction in moisture contents in the first 12 days. The moisture content of Samples 2 and 3 was smaller than that of Sample 1. The moisture contents of Samples 8 and 9 decreased from $104.32 \%$ to $21.16 \%$, which were smaller than any other samples with different treatments.

Figure 4 presents changes in the area contraction ratio with time during the drying process. The area contraction ratio of a soil sample is defined as the ratio of reduction in the area to the original area of soil sample. The area contraction ratios of all samples increased with time during drying. During the first 10-12 days, the area contraction ratios quickly increased from the range of $0.09 \%-0.82 \%$ to $2.79 \%-7.77 \%$. Between the 12th and 28th day of the drying period, the 


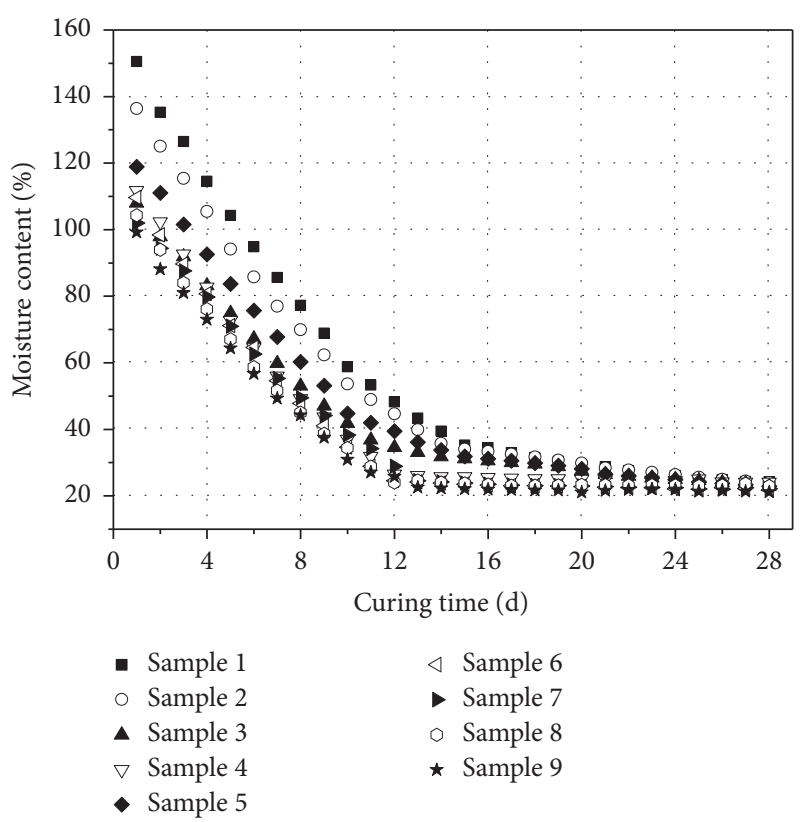

FIGURE 3: Variations of moisture content of solidified sewage sludge with time during curing.

increases in the area contraction ratios slowed down, ranging from $2.79 \%-7.77 \%$ to $5.74 \%-11.03 \%$. Among all the samples, the area contraction ratio of Sample 1 had the quickest increasing rate, reaching the maximum value of $11.03 \%$ on the 28 th day. Sample 9 always had the smallest increase in the area contraction ratio, with a value of $5.74 \%$ on the 28 th day.

Water in the solidified sewage sludge was mainly from the water in the sewage sludge. The higher the sewage sludge content was, the higher the initial moisture content would be. The shrinkage of the solidified sewage sludge was mainly caused by loss of water. The larger the loss of water, the larger the shrinkage would be. The magnitude of shrinkage of the solidified sewage sludge during drying depended upon the relative amounts of gangue, cement, and clay, which formed the skeleton of solidified soils through hydration reaction. If the content of inorganic matter was high, then the hydration reaction of cement could be accelerated [13]. The cement and clay hydration processes will reduce the amount of water available for evaporation during drying, which in turn reduce the shrinkage. It was considered that fiber could increase the soil strength and reduce the cracking during drying but did not have effect on reducing drying shrinkage.

That being said, the results as presented by Figures 3 and 4 are reasonable. Among all soil samples, Sample 1 contained the largest content of sewage sludge and the least amounts of gangue, cement, and clay. Consequently, it had the largest initial water content as shown in Figure 3. Due to the fact that it had the largest water-cement ratio, the hydration reaction of cement was weaker. Consequently more water was available for evaporation during drying process. Less coal gangue also led to insufficient skeleton effect to prevent drying shrinkage. All these resulted in the largest water loss and drying shrinkage as shown in Figures 3 and 4.
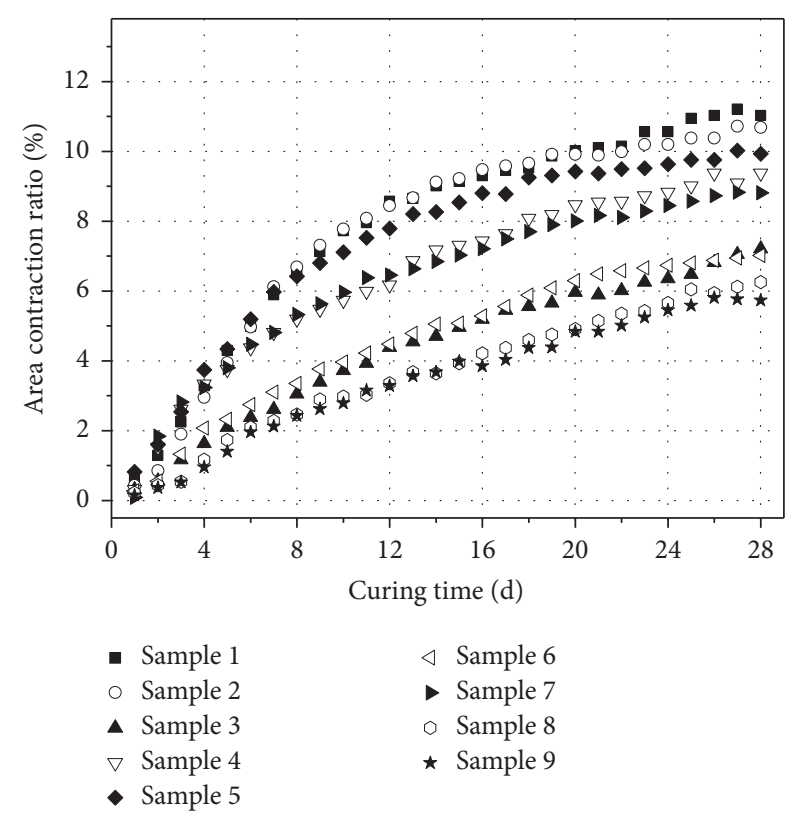

FIGURE 4: Changes in the area contraction ratio of the solidified sewage sludge with time during curing.

By contrast, Samples 8 and 9 contained the least content of sewage sludge and subsequently much smaller initial water content. They also had the largest amount of cement, which consumed more water during cement hydration process. The percentages of gangue in mass were also among the highest for the two samples, which could effectively form soils skeleton to prevent drying shrinkage [14]. Consequently, they had the smallest area contraction ratios with time during drying as shown in Figure 4.

The variations of cracking intensity factor (CIF) of the solidified sewage sludge with time during drying are presented in Figure 5. The CIF of samples with different mix proportions generally increased with the drying time. Among all samples, the CIF of Sample 6 increased most significantly and was much larger than any other samples. It reached the maximum value of 0.0323 on the 30 th day. The CIF values were the smallest for Samples 8 and 9 and did not change significantly during the drying. The CIF of Samples 8 and 9 were 0.0031 and 0.0023 , respectively, on the 28th day, indicating that very few cracks were generated.

The CIF of Sample 1 was similar to those of Samples 8 and 9 between 0 and 18 days of drying, but continued to slowly increase after that, indicating there were still small cracking occurrences after long time of drying process. As shown in Table 5, Sample 1 had the highest water-cement ratio and the lowest contents of gangue and fiber. Figure 3 indicates that the sample had a significant amount of water loss. Figure 4 indicates that it had the largest area contraction ratio. All these indicate that, in sample, the amount of gangue and cement was not sufficient to generate a soil skeleton which can significantly prevent the drying shrinkage. The decrease in the solidified sludge volume was caused by a relatively uniform loss of water, which led to very few cracking occurrences. 


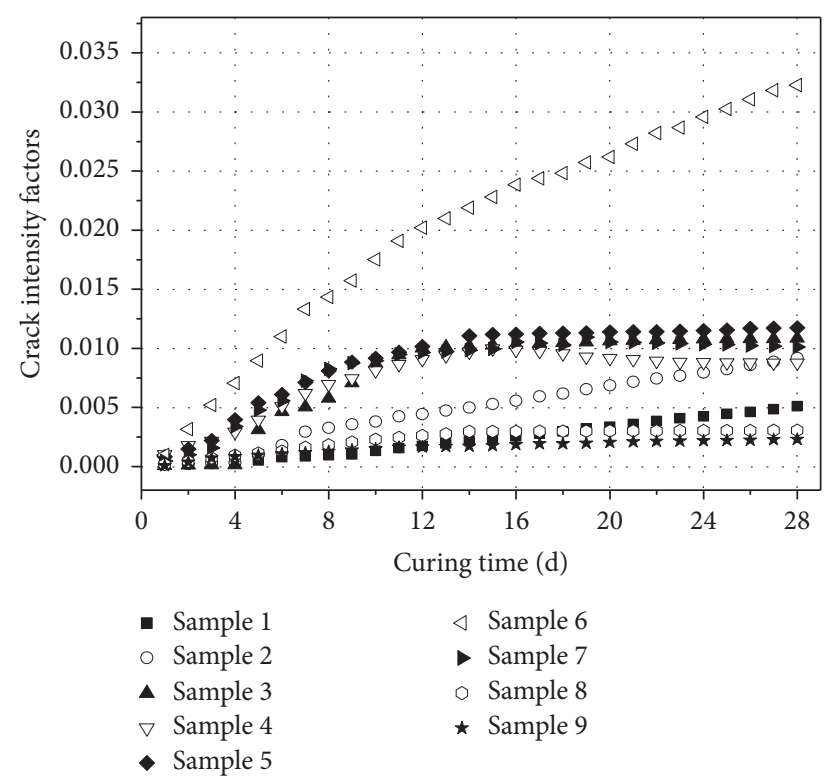

FIGURE 5: Variations of crack intensity factors of the solidified sewage sludge with time during drying.

Due to the much less cement hydration reaction, the drying shrinkage lasted for a long period of drying process and cracking occurrences, although very few, continued for a long time.

For Samples 2, 3, 4, 5, and 7, the final cracking intensity factors were nearly the same. The CIF of Sample 2 constantly increased during the entire drying process, whereas those of Samples 3, 4, 5, and 7 quickly increased initially, reached the maximum value between the 10th and 14th day, and then slightly decreased to certain constant values. While Sample 2 was similar to Sample 1, the reduction in the CIF in Samples $3,4,5$, and 7 was caused by partial healing of cracks due to drying shrinkage of the solidified samples.

During the drying process, Sample 6 always had the highest CIF. This is mainly attributed to the fact that Sample 6 had the highest content of coal gangue and relatively less amount of cement, fiber, and clay. The gelatinous substance $(\mathrm{CSH})$ produced by hydration reaction of cement was not sufficient to fill the pores in the solid skeleton formed by the coal gangue, nor did it result in effective bonding between the hydration products and hydrophilic polypropylene fiber and coal gangue [15]. Consequently, the cementation effect formed in the solidified sludge was more of a small-area contact bonding, which was fairly weak and more inclined to cracking during drying shrinkage. In contrast, although Samples 8 and 9 had the same high contents of coal gangue, they contained higher contents of cement and clay. The coal gangue formed a soil skeleton with relatively large pore size, which were filled, and more importantly, cemented by the gelatinous substance $(\mathrm{CSH})$ produced by hydration reaction of cement and the clay. The strong cementation effect can form a very strong soil skeleton which had low hydraulic conductivities and can effectively resist the cracking caused by drying shrinkage and external forces.

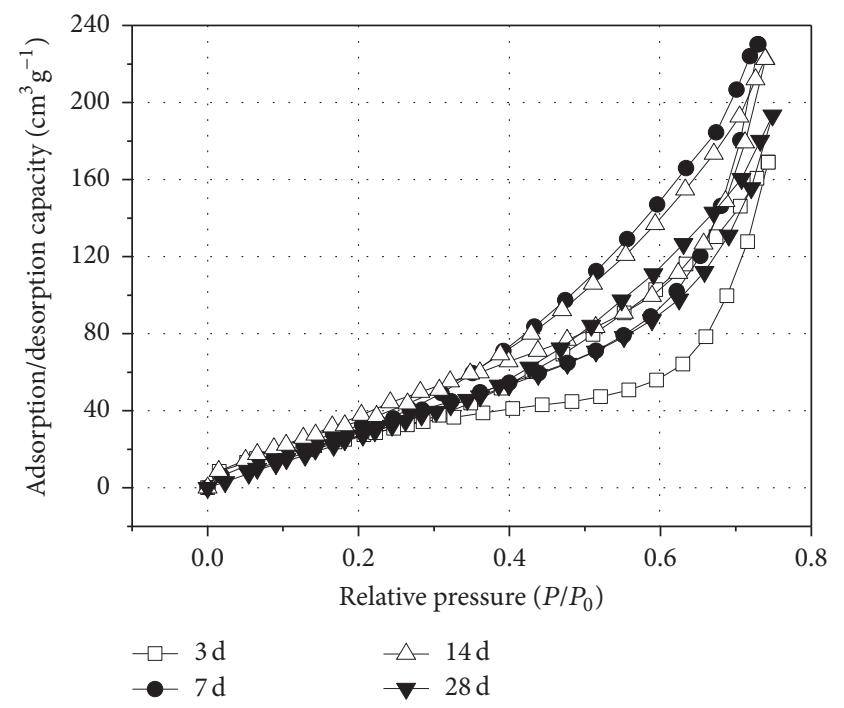

FIgURE 6: Adsorption-desorption curves of Sample 4 at different curing times.

Considering that Samples 4, 7, 8, and 9 had the best overall performances in solidification, only results for these 4 samples were presented for further discussions in terms of pore, shear strength, and hydraulic conductivity, while the rest of solidified samples were not considered in the following sections.

3.2. Pores. The adsorption-desorption curves at different curing times were similar for all solidified samples (i.e., Samples 4, 7, 8, and 9). Thus, Sample 4 were selected as a representative of all solidified samples to demonstrate the changes in adsorption-desorption curves for the soils at different curing times, which is shown in Figure 6. As can be seen in Figure 6, the adsorption curve of Sample 4 coincided with its desorption curve when relative pressure ratio $\left(P / P_{0}\right)$ ranged from 0 to 0.3 , where $P$ is the partial pressure of nitrogen and $P_{0}$ is the saturated vapor pressure of liquid nitrogen. When $P / P_{0}$ was larger than 0.35 , the adsorptiondesorption curves at different curing times exhibited some typical $\mathrm{H}_{2}$ hysteresis loops [16]. The hysteresis loop of Sample 4 was the largest at the end of three days of curing and continuously decreased as the curing time increased.

Figure 7(a) shows the relationship between differential pore volume and the equivalent pore diameter of Sample 4 at different curing times. Figure 7(b) shows the relationship between the cumulative pore volume and the equivalent pore diameters for Sample 4 at different curing times. As can be seen in Figure 7(a), all the pores in Sample 4 had pore sizes ranging from $1.7 \mathrm{~nm}$ and $8.5 \mathrm{~nm}$, which can be classified as micropore and mesopore [17]. At the end of three days of curing, the pore sizes were mainly ranging from 3 to $7.8 \mathrm{~nm}$. Two peak values were identified on the pore distribution curve, with approximate pore sizes of 2.0 and $3.2 \mathrm{~nm}$, respectively. As the curing time continued to the end of seven days, there were three peaks on the pore distribution curve, with equivalent pore diameters of $2.13 \mathrm{~nm}, 3.5 \mathrm{~nm}$, and 


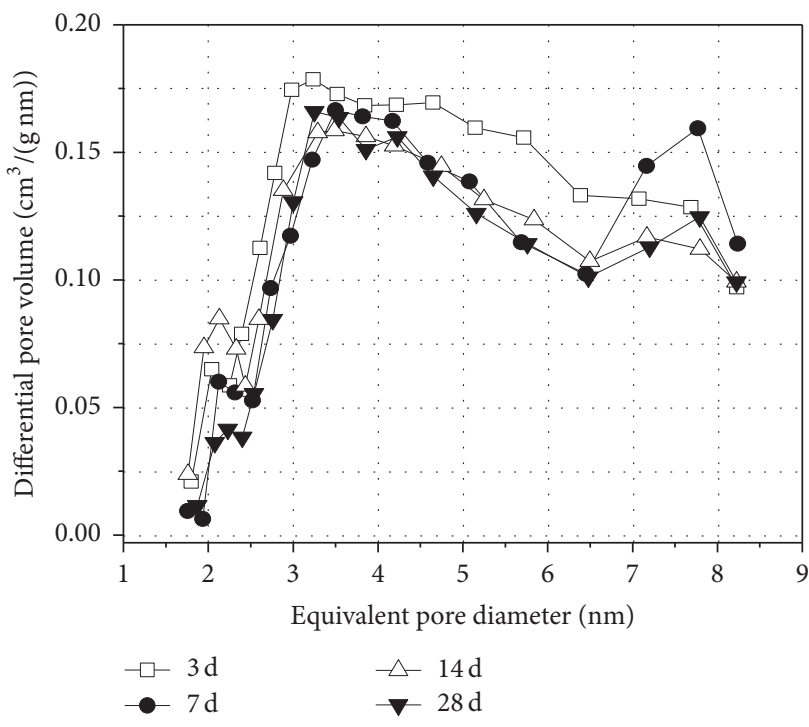

(a)

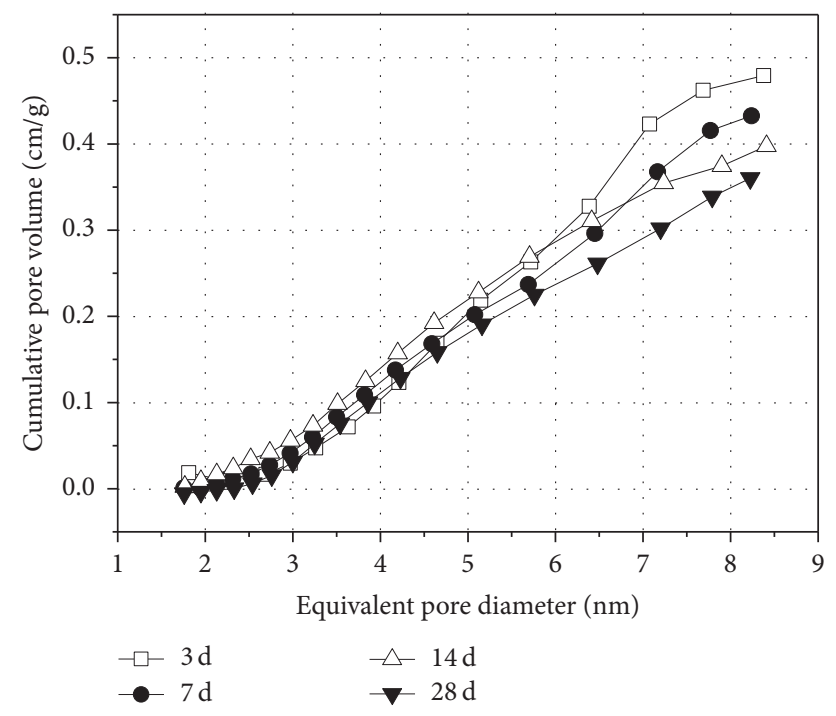

(b)

FIGURE 7: Relationship between differential pore volume and the equivalent pore diameter of Sample 4 at different curing times.

$7.77 \mathrm{~nm}$, respectively. It was clear that the number of pores ranging from $3.5 \mathrm{~nm}$ to $6.5 \mathrm{~nm}$ was reduced. At the end of 14 days of curing time, a centralized tendency of the peak value of the distribution curve presented and formed a low and two high peaks. The low peak appeared at $1.5-2.5 \mathrm{~nm}$, and the two high peaks appeared at 3-4.5 and 7-8 $\mathrm{nm}$. The low peak at 1$2 \mathrm{~nm}$ became more centralized on 14th day than on the 7 th day; the peak became smaller on the 28th day of the curing period. The high peak at 3-4.5 $\mathrm{nm}$ became more centralized as the curing period continued. The high peak at $7-8 \mathrm{~nm}$ lowered on the 28th day of the curing period. It is also noted that, at the end of 14 days of curing, the number of pore with pore sizes varying from $5 \mathrm{~nm}$ to $6.5 \mathrm{~nm}$ increased, which was likely due to the drying cracking during the curing process.

Figure 8 shows the changes in the total pore volume with curing times for different solidified sludge. As can be seen in Figure 8, the total pore volumes for all solidified soils decreased with an increase in the curing time. The reductions were significant at the intimal stage of the curing, and slowed down with curing time. Sample 9 had the largest initial pore volume, and Sample 4 had the smallest total pore volume. Finally all solidified soils reached near the same final total pore volume.

Figure 9 illustrates the changes in the specific surface areas with curing times for different solidified sludge, which are similar to those in Figure 8. The total pore volume and specific surface area of Sample 9 decreased from the range between $0.89 \mathrm{~cm}^{3} / \mathrm{g}$ and $0.06 \mathrm{~cm}^{2} / \mathrm{g}$ on third day to $0.40 \mathrm{~cm}^{3} / \mathrm{g}$ and $0.02 \mathrm{~cm}^{2} / \mathrm{g}$ on the 28 th day during the curing period, respectively. The total pore volume and specific surface area of Samples 7 and 8 were both smaller than those of Sample 9. On the third day of curing, total pore volume of Samples 7 and 8 were 0.60 and $0.64 \mathrm{~cm}^{3} / \mathrm{g}$, respectively. The specific surface area of Samples 7 and 8 were 0.03 and $0.04 \mathrm{~cm}^{2} / \mathrm{g}$, respectively. However, on the 28th day of curing,

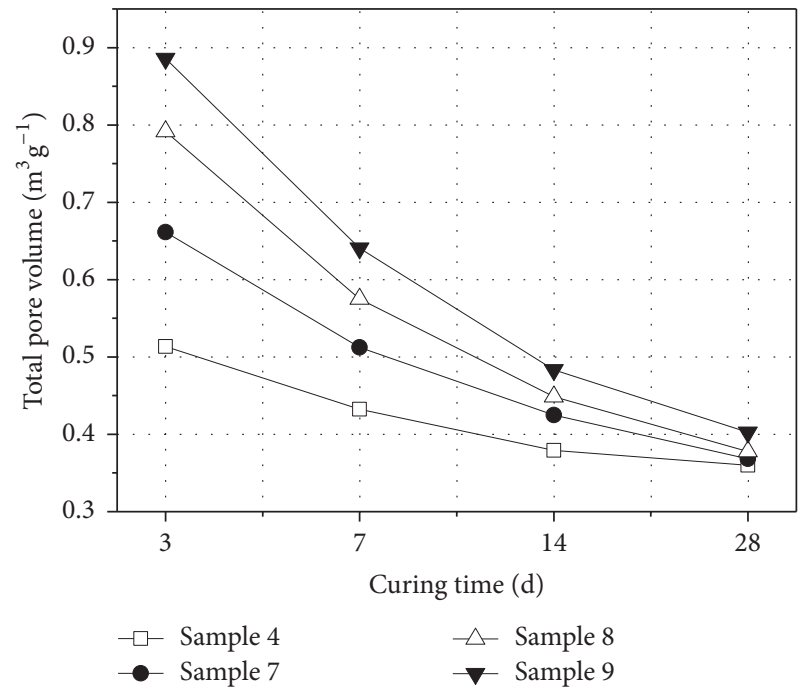

FIGURE 8: Changes in the total pore volume with curing times for different solidified sludge.

the total pore volume of Samples 7 and 8 declined to 0.37 and $0.38 \mathrm{~cm}^{3} / \mathrm{g}$, and their specific surface area also declined to 0.01 and $0.01 \mathrm{~cm}^{2} / \mathrm{g}$, respectively. The total pore volume of Sample 4 was the smallest, and it declined to $0.36 \mathrm{~cm}^{3} / \mathrm{g}$ on the 28th day of curing.

The changes in the hysteresis loop, pore volume curve, and specific surface area could be explained as follows. First, at the very beginning of the curing period, the soil skeleton was mainly dominated by the coal gangue. The hydration reaction was not fully developed and the filling effect of the hydration product on the soil skeleton was insignificant or negligible. As the curing continued, some of the cement started hydration reaction. This generated nucleation 


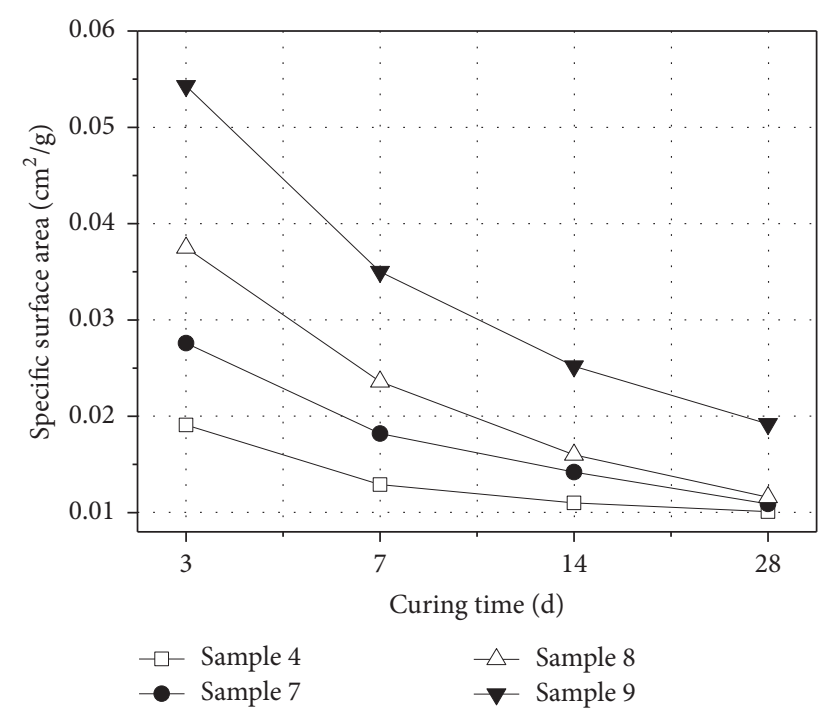

FIGURE 9: Changes in the specific surface areas with curing times for different solidified sludge.

between the $\mathrm{CSH}$ and hydration product (e.g., calcium hydroxide), which also encapsulated some clay particles. This process filled some of the mesopores and resulted in reductions in the pore volumes and specific surface area of the mesopores [18]. Second, part of the calcium hydroxide produced in the hydration reaction process reacted with the carbon dioxide in air and produced insoluble calcium carbonate, which filled some of the mesopores and resulted in decreases in the pore volumes of the mesopores. Third, during the curing period, cement reacted with water in the clay and resulted in drying shrinkage, which also led to reductions in the pore sizes of the solidified sludge. Fourth, during the drying process, there might be cracking due to drying shrinkage, which could potentially increase the pore sizes and total pore volume.

3.3. Shear Strength. Figure 10 presents the deviator stress versus axial strain curves of Sample 4 at different curing times. Three different levels of confining pressure were used to evaluate the shear strength of Sample 4 at different curing times, which were 50,100, and $150 \mathrm{kPa}$, respectively. Figures $10(\mathrm{a}), 10(\mathrm{~b})$, and 10 (c) indicate that, at the end of the $3 \mathrm{rd}, 7 \mathrm{th}$, and 14th day of the curing period, the axial strain increased quickly with the increases in the deviator stress in the range from $0 \%$ to $4 \%$ and then stabilized to constant values in the range from $4 \%$ to $11 \%$, which belonged to typical strain-hardening similar to normally consolidated clays or loose sand. In contrast, at the end of the 28th day of the curing period, the behavior of Sample 4 exhibited a typical strain-softening behavior similar to overconsolidated clays or densely compacted sand. The deviator stress increased with an increase in the a axial strain in the range from $0 \%$ to $3 \%$, reached peaks at strains between $3 \%$ and $3.5 \%$, and then decreased with the increase in the a axial strain in the range from $3.5 \%$ to $11 \%$. The strain-softening effect increased with a decrease in the confining pressure.
The changes in the stress-strain behavior of Sample 4 at different curing times can be explained as follows. At the initial stages of curing, the hydration of the cement was not fully developed. The soil skeleton was formed by coal gangue, fiber, and small amount of CSH generated by cement hydration. There was little bonding effect between these constituents and they can move relatively easily under deviator stress and exhibit strain-hardening behavior similar to normally consolidated clays or loose sand. At the end of the 28th day as shown in Figure 10(d), when curing reached a certain extent, the cement hydration reaction was fully developed. There was sufficient CSH to provide cementation to bond different constituents together to form strong soil skeleton just like the cementation effect typically existing in overconsolidated soils $[19,20]$.

Figure 11 presents the relationship between cohesion (c) of the solidified sewage sludge samples $(4,7,8$, and 9) and the curing times. As can be seen in Figure 11, cohesions for all the solidified sewage sludge samples increased with the curing time. The changes in cohesions of the solidified sewage sludge samples were insignificant in the first seven days, and then increased significantly after that. Sample 8 had the largest increase in the cohesion, varying from 14.8 to $55.4 \mathrm{kPa}$. It was followed by Sample 4, changing from 12.6 to $45.8 \mathrm{kPa}$. The increases in cohesion for Sample 9 were much smaller, while Sample 7 had the least increases from 11.2 to $19.8 \mathrm{kPa}$.

Figure 12 illustrates changes in the internal frictional angle $(\varphi)$ of the four solidified sewage sludge samples as a function of the curing times. It was found that the internal frictional angle $(\varphi)$ of the four solidified sewage sludge samples increased nearly linearly with the curing times. Although there were small differences in the internal frictional angle $(\varphi)$ between Samples 4 and 7 and Samples 8 and 9 at the end of 14 days of curing, overall the changes in the internal frictional angle $(\varphi)$ of the four solidified sewage sludge samples were very similar.

The increases in the cohesion and internal frictional angle of the solidified sewage sludge samples were mainly caused by the cementation as well as formation of the new and stronger soil skeleton during the cement hydration process. The movements of soil particles were restrained by the cementation inside the sample, thus controlling the cracking of the samples [21]. At the initial stages of the curing, the hydration reaction of the cement was not fully developed, the solidified sewage sludge samples still had high content of water and the cementation and frictional resistance inside the soil were weak. Hence, both the cohesions and internal frictional angle of the solidified sewage sludge samples were small. As time went, the water contents in the solidified sewage sludge samples declined due to cement hydration process. In the meantime, the CSH generated by cement hydration started to bond different constituents in the solidified soils together to form stronger new soil skeleton. Both effects can result in increases in the cohesion, internal frictional angle, and therefore the soil shear strength. The cohesion of Sample 8 was the highest among all solidified soils at the end of 28 days of curing because the content of sewage sludge was relatively low and the contents of cement and clay were high. When the hydration reaction was completely finished, the hydration product 


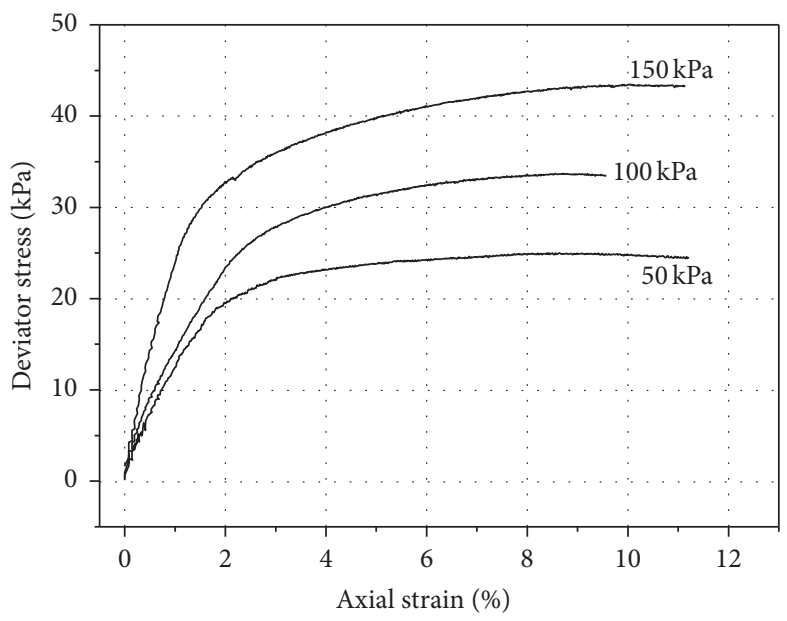

(a) Curing for 3 days

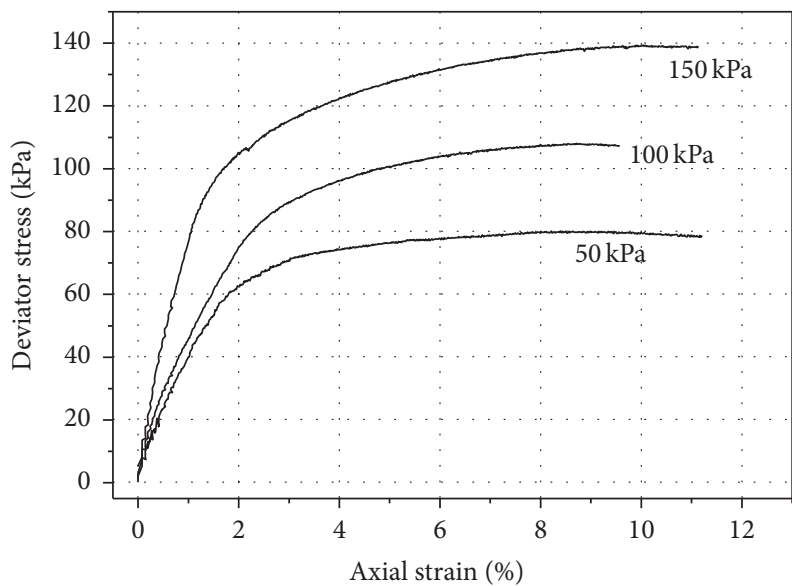

(c) Curing for 14 days

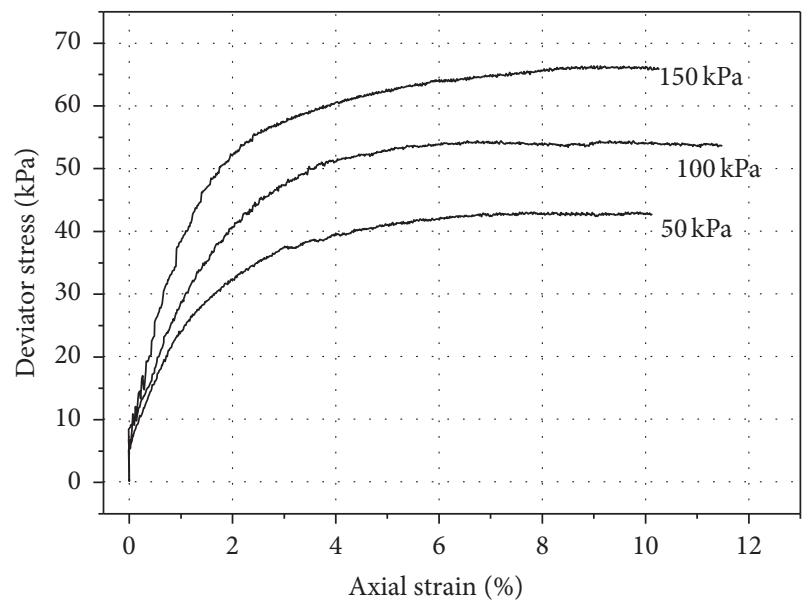

(b) Curing for 7 days

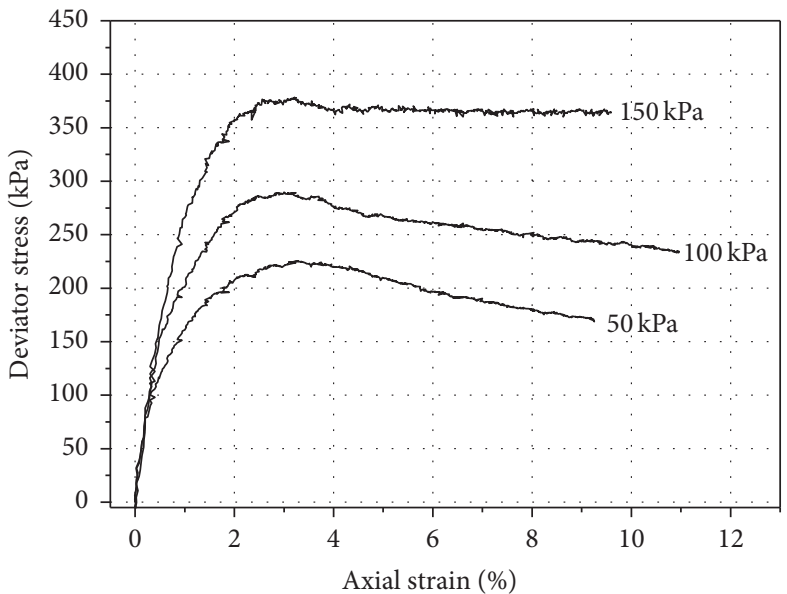

(d) Curing for 28 days

FIGURE 10: Relationship between deviator stress and axial strain for Sample 4 at different curing times.

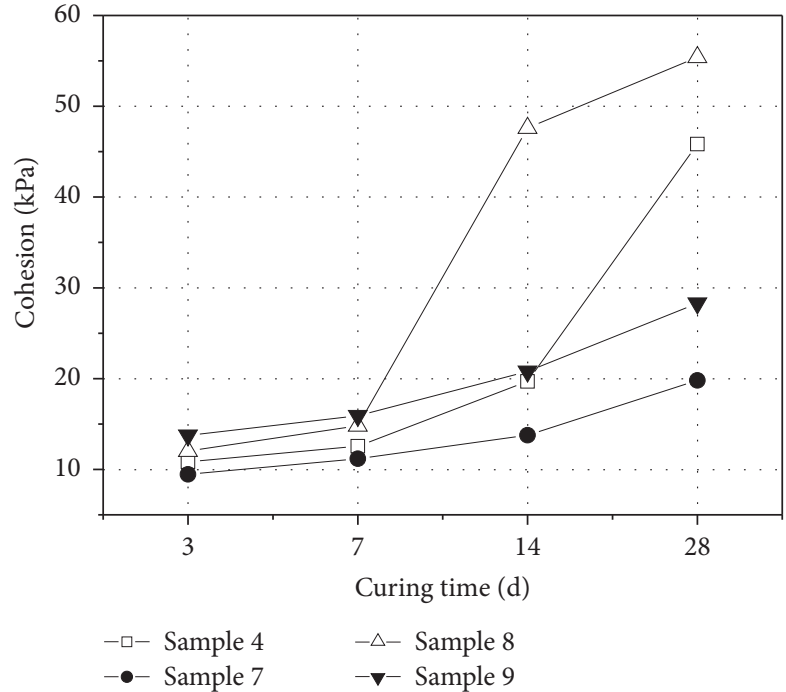

FIGURE 11: Relationship between cohesion of the solidified sewage sludge and the curing time.

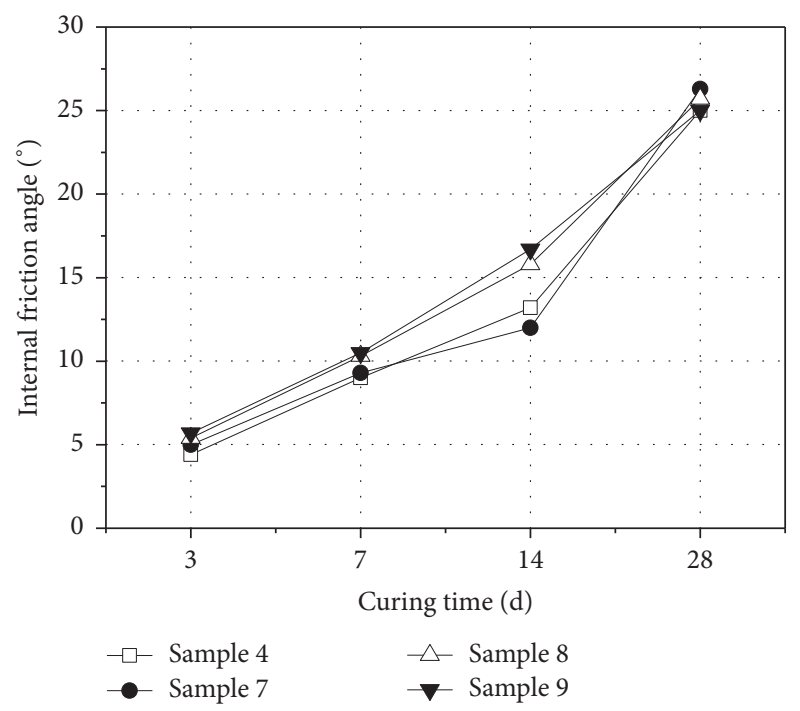

FIGURE 12: Relationship between internal frictional angle of the solidified sewage sludge and the curing time. 


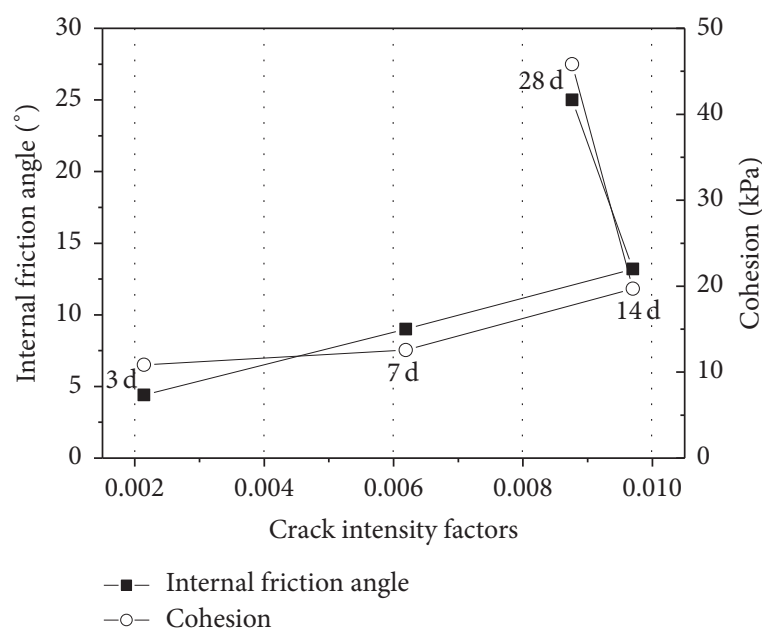

(a) Sample 4

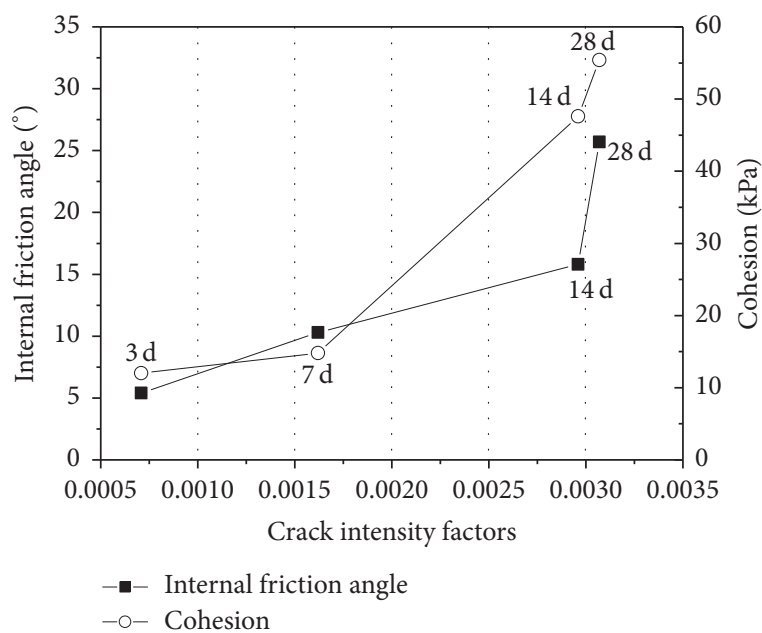

(c) Sample 8

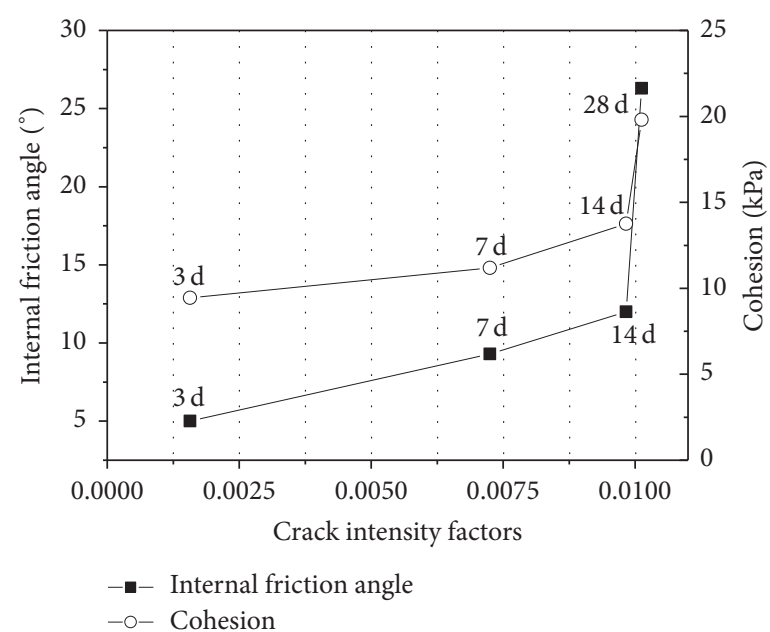

(b) Sample 7

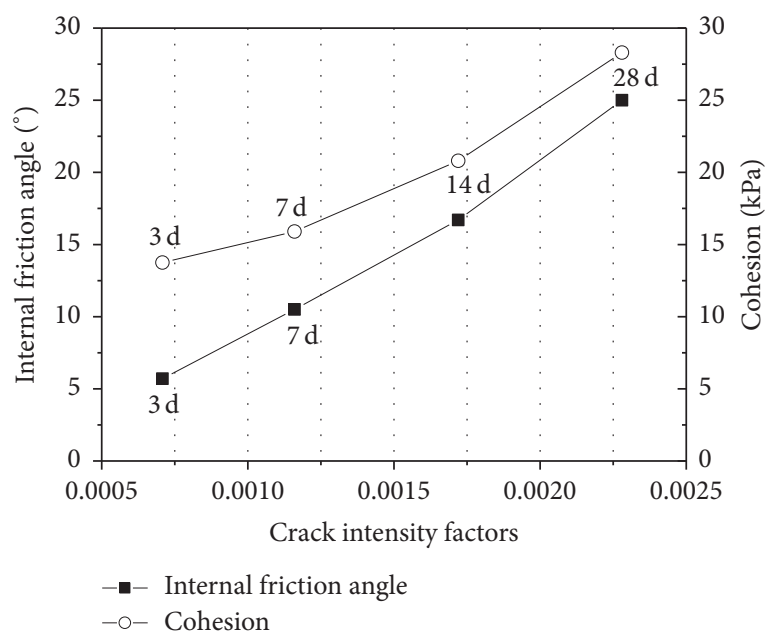

(d) Sample 9

FIGURE 13: Relationship between cohesion, internal friction angle, and cracking intensity factors for different solidified soils at different curing times.

effectively cemented fiber and coal gangue together [22]. The internal friction angles of all solidified soils were relatively large, the interlocking force between particles strengthened and the cementation between CSH was restrained. Samples with larger cohesive and internal friction angle (i.e., Samples 7,8 , and 9) effectively inhibited the consolidated sludge cracking as discussed previously.

As discussed previously, CIF indicates the number and magnitudes of cracks in the soil samples. More cracks in the soil samples often imply lower soil strength (cohesion and internal frictional angle). Figure 13 shows the relationship between cohesion, internal friction angle and cracking intensity factors for different solidified sludge samples at different curing times. Figure 13 shows that for Samples 7, 8, and 9, the CIF, increased with curing time. For Sample 4, the CIF first increased with curing times in the first 14 days of curing, and then decreased with curing time after that. The cohesions and internal frictional angles for all of the four solidified samples increased with curing time. At the first glance, a conclusion might be drawn that the cohesions and internal frictional angles of the solidified soils increased with the CIF, which is conflicting with the common sense as mentioned above. An in-depth analysis indicates Figure 13 is reasonable since there were two factors influenced the cohesions and internal frictional angles of the solidified sludge: one is cementation caused by the cement hydration process, which led to increases in the cohesions and internal frictional angles with curing time; the other is cracking occurrence in the solidified sludge, which resulted in decreases in shear strength [23]. The final results depended upon the combined effect of these two effects. Figure 13 indicates that, during the curing process, the cementation caused by the cement hydration process was dominant in controlling the shear strength of the solidified sludge.

3.4. Hydraulic Conductivity. Figure 14 shows the hydraulic conductivities of the four solidified sewage sludge at different curing times. Figure 14 indicates that hydraulic conductivities of the four solidified sewage sludge decreased as the curing time increased. The reductions in the hydraulic conductivities 


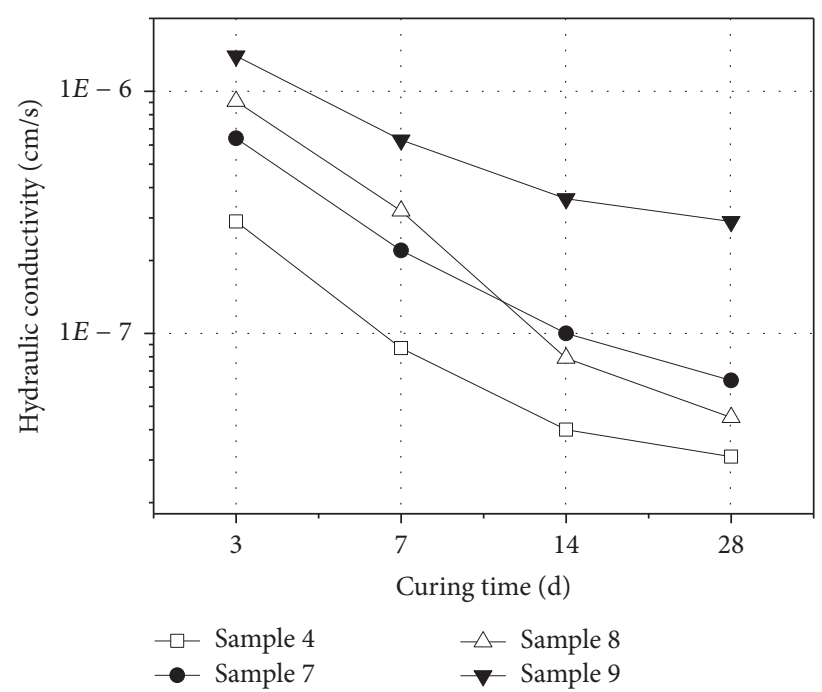

FIGURE 14: Hydraulic conductivities of the solidified sewage sludge at different curing times.

were initially rapid and then slowed down. Compared with other solidified sludge, the hydraulic conductivities of Sample 9 were the largest at all different curing times, whereas those of Sample 4 were always the smallest. The hydraulic conductivities of Samples 7 and 8 were between those of Samples 4 and 9 at the same curing period. As can be seen in Figure 14, when the curing time was less than 7 days, the hydraulic conductivities of Sample 7 were higher than those of Sample 8. After 7 days of curing, the hydraulic conductivities of Sample 7 were lower than those of Sample 8 at the same curing time.

The hydraulic conductivities of the solidified sewage sludge at different curing time are related to constituents of the mixers and the hydration processes of clay and cement. At the initial stage of curing, the pore volumes in the solidified soils were dominated by the soil skeletons formed by the coal gangue when the cement was not fully hydrated. As can be seen in Table 5, Sample 9 had the highest content of coal gangue ( $20 \%$ by weight) and therefore the highest hydraulic conductivity at the end of three days of curing. It was followed by Sample 8 ( $15 \%$ of coal gangue by weight) and then Sample 7 (10\% of coal gangue by weight), so were their initial hydraulic conductivities. Samples 7 and 4 had the same content of $10 \%$ of coal gangue by weight, which supposed to have the same hydraulic conductivity. However, the initial hydraulic conductivity of Sample 4 was lower than that of Sample 7 due to its higher clay content of $10 \%$ by weight. Clay could absorb water relatively quickly during its hydration (wetting) process. Consequently, it can dehydrate the sewage sludge to cause drying shrinkage. This can result in smaller pore size and lower hydraulic conductivity. As the curing proceeded, the cement hydration reaction was fully developed. The generated CSH and insoluble calcium carbonate can fill the pores in the soil skeleton and to provide cementation to bond different constituents together to form new soil skeleton with smaller pore sizes. Consequently, the hydraulic conductivities of the solidified soils decreased with the increasing curing times. Another factor which influenced the cement hydration

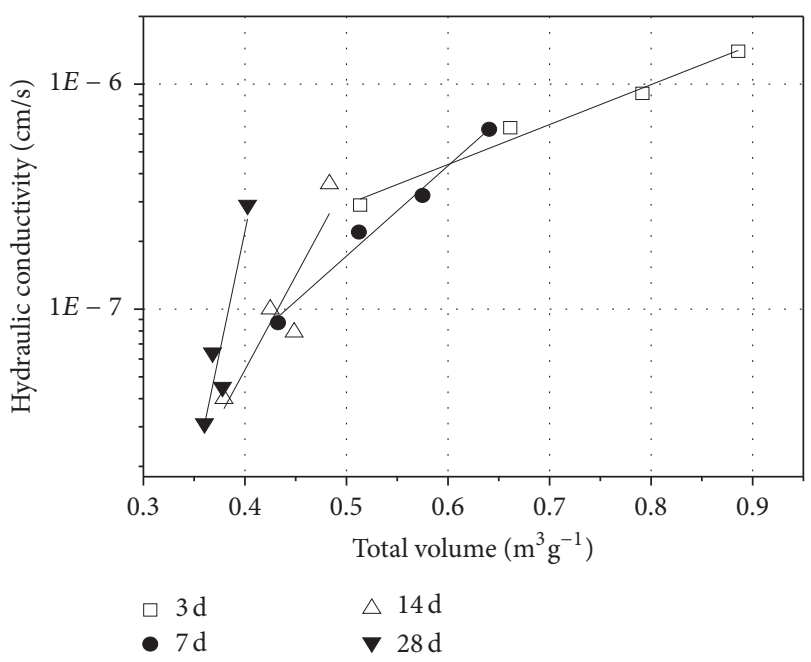

FIGURE 15: Relationship between the total pore volume and hydraulic conductivity of the solidified sewage sludge.

process was the clay content. Clay can facilitate the hydration reaction of cement by interacting with the inorganic matter in the sewage sludge. This might be the reason why after 7 days of curing, the decrease in hydraulic conductivity for Sample 8 with $10 \%$ of clay content accelerated compared with Sample 7 with $5 \%$ of clay content. At the end of three days of curing, the hydraulic conductivities of Samples 9 and 4 were $2.9 \times$ $10^{-7} \mathrm{~cm} / \mathrm{s}$ and $1.4 \times 10^{-6} \mathrm{~cm} / \mathrm{s}$, respectively. On the 28th day of curing, the hydraulic conductivities of Samples 9 and 4 were $3.1 \times 10^{-8}$ and $2.9 \times 10^{-7} \mathrm{~cm} / \mathrm{s}$, respectively. During the entire curing period, the hydraulic conductivities of Samples 7 and 8 declined from $6.4 \times 10^{-7}-9.1 \times 10^{-7}$ to $4.5 \times 10^{-8}$ $6.4 \times 10^{-8} \mathrm{~cm} / \mathrm{s}$, respectively. At the end of 28 days of curing, Samples 4,7 , and 8 had hydraulic conductivities of less than 1 $\times 10^{-7} \mathrm{~cm} / \mathrm{s}$, which satisfied the permeability requirement of the landfill liner structure, and can be used in landfill structure [24].

Figure 15 shows the relationship between the hydraulic conductivities of the solidified sludge and the total pore volumes at different curing times. Figure 15 indicates that the total pore volumes of all solidified sludge samples decreased with increases in the curing times, which was consistent with the previous analyses. In the meantime, the logarithms of the hydraulic conductivities were nearly linearly proportional to the increases in the total pore volume, which is completely reasonable since hydraulic conductivity is a measurement of how easily water can flow through the soil. The larger the pore size, the less resistances the water will experience when flow through the soils and the higher hydraulic conductivity. It is also found in Figure 15 that at the same total pore volume, the hydraulic conductivities for different solidified samples were different. This is reasonable since hydraulic conductivity is not only dependent upon the total pore volume, but also the pore size distribution. If the microstructures of the solidified soils were different, their hydraulic conductivities will be different. For example, as discussed previously, Sample 9 had the highest content of coal gangue, which likely formed a soil 
skeleton with fewer but larger pore sizes and led to higher hydraulic conductivity, while, for Sample 4, it has the lowest content of coal gangue but high cement and clay content, and it was more inclined to form a soil skeleton with more micropores with smaller pore size. At the same total pore volume, water is much easier to flow through soils with larger pore sizes, which implies a higher hydraulic conductivity.

\section{Conclusions}

This paper evaluated the feasibility of using a skeleton-building method to solidify municipal sewage sludge in which coal gangue was used as skeleton material and cement, clay, and fiber were used as cementation and filling materials. Comprehensive tests including shrinkage and cracking, nitrogen adsorption, triaxial shearing and the flexible wall permeability tests were performed to evaluate the hydraulic and mechanical behavior of municipal sewage sludge solidified with different proportions of coal gangue, cement, clay, and fiber at both the macroscopic and microstructural levels. Based upon the test results and analyses, the following conclusions are drawn:

(1) The proposed mix design for solidifying municipal sewage sludge through the skeleton-building method by using the coal gangue, cement, clay, and fiber significantly reduced moisture content from initial value of higher than $100 \%$ to final value of less than $25 \%$. The area contraction ratio and crack intensity factors of the all solidified soils generally increased with curing time.

(2) The changes in the hysteresis loop, pore volume curve, and specific surface area were related to the cement hydration process during curing. The adsorptiondesorption curves at different curing times were similar for all solidified samples. The adsorption curve coincided with its desorption curve when relative pressure ratio $\left(P / P_{0}\right)$ was small (from 0 to 0.3$)$. When $P / P_{0}$ was larger, the adsorption-desorption curves at different curing times exhibited some typical $\mathrm{H}_{2}$ hysteresis loops. The total pore volumes for all solidified soils decreased with an increase in the curing time. The reductions were significant at the initial stage of the curing, and slowed down with curing time. Finally all solidified soils reached near the same final total pore volume. The specific surface areas for different solidified sludge decreased with an increase in the curing time in a similar way.

(3) At the initial stage of the curing, the solidified sludge exhibited typical strain-hardening behavior similar to normally consolidated clays. At the end of the curing period, the solidified sludge exhibited strain-softening behavior similar to overly consolidated clays. Both cohesions and internal frictional angles of the solidified sludge increased with curing time. The increases in cohesions of the solidified sludge were insignificant in the first seven days, and then increased significantly after that. The internal frictional angle $(\varphi)$ of the solidified sewage sludge samples increased nearly linearly with the curing times.

(4) The hydraulic conductivities of the solidified sewage sludge decreased as the curing time increased. The logarithms of the hydraulic conductivities were nearly linearly proportional to the increases in the total pore volume. The hydraulic conductivities of the solidified sewage sludge at different curing time are related to constituents of the mixers and the hydration processes of clay and cement. If the microstructures of the solidified soils were different, their hydraulic conductivities will also be different. Sample 9 had the highest content of coal gangue, which likely formed a soil skeleton with fewer but larger pore sizes and led to higher hydraulic conductivity, while, for Sample 4, it has the lowest content of coal gangue but high cement and clay content, and it was more inclined to form a soil skeleton with more micropores with smaller pore size and therefore lower hydraulic conductivity. At the same total pore volume, water is much easier to flow through soils with larger pore sizes, which implies a higher hydraulic conductivity.

(5) Through the comprehensive test results, the mechanism of the proposed skeleton-building method can be explained as follows. Coal gangue initially formed soil skeleton at the initial stage of the curing. As the curing continued, the cement started hydration reaction and generated nucleation between the $\mathrm{CSH}$ and hydration product (e.g., calcium hydroxide), which also encapsulated some clay particles. This process filled some of the mesopores and resulted in reductions in the pore volumes and specific surface area of the mesopores. Part of the calcium hydroxide produced in the hydration reaction process reacted with the carbon dioxide in air and produced insoluble calcium carbonate, which filled some of the mesopores and resulted in decreases in the pore volumes of the mesopores. During the curing period, cement reacted with water in the clay and resulted in drying shrinkage, which also led to reductions in the pore sizes of the solidified sludge. There might be cracking due to drying shrinkage, which could potentially increase the pore sizes and total pore volume.

(6) The municipal sewage sludge solidified with coal gangue, cement, and clay using the skeleton-building method, when properly designed (e.g., Sample, 4, 7, and 8), has low cost, high shear strength, low hydraulic conductivity, and high resistance to cracking caused by drying shrinkage, which can be used in the structure of landfill liner.

\section{Competing Interests}

The authors declare that there is no conflict of interests regarding the publication of this paper. 


\section{Acknowledgments}

The authors would like to express their great appreciation for funding provided by the "National Natural Science Foundation of China (11672216 and 51474168)," the "Natural Science Fund of Hubei Province (2016CFB636)," the "Open Research Fund of State Key Laboratory of Geomechanics and Geotechnical Engineering, Institute of Rock and Soil Mechanics, Chinese Academy of Science (Z015006)," and the "100 Gifted People Plan of Hubei Province, China."

\section{References}

[1] A. C. Sophia and K. Swaminathan, "Assessment of the mechanical stability and chemical leachability of immobilized electroplating waste," Chemosphere, vol. 58, no. 1, pp. 75-82, 2005.

[2] H. Tremblay, S. Leroueil, and J. Locat, "Mechanical improvement and vertical yield stress prediction of clayey soils from eastern Canada treated with lime or cement," Canadian Geotechnical Journal, vol. 38, no. 3, pp. 567-579, 2001.

[3] G. G. Qian, Y. L. Cao, and P. C. Chui, "Tay Utilization of MSWI ash for stabilization/solidification of industrial waste sludge," Journal of Hazardous Materials, vol. 129, no. 1-3, pp. 274-281, 2006.

[4] S. Valls and E. Vàzquez, "Stabilisation and solidification of sewage sludges with Portland cement," Cement and Concrete Research, vol. 30, no. 10, pp. 1671-1678, 2000.

[5] L. Li, W. Zhu, and C. Lin, "Experimental study on sludge solidification by using skeleton construction method," China Water and Wastewater, vol. 21, no. 6, pp. 41-43, 2005.

[6] L. Dong, S. Ding, L. Xie, L. Cai, and H. Yang, "Walnut shell used as skeleton builder for improving sludge dewatering properties," Chinese Journal of Environmental Engineering, vol. 10, no. 1, pp. 365-369, 2016.

[7] D. Y. Lee, S. R. Jing, and Y. F. Lin, "Using seafood waste as sludge conditioners," Water Science and Technology, vol. 44, no. 10, pp. 301-307, 2001.

[8] E.-H. Kim, J.-K. Cho, and S. Yim, "Digested sewage sludge solidification by converter slag for landfill cover," Chemosphere, vol. 59, no. 3, pp. 387-395, 2005.

[9] K. B. Thapa, Y. Qi, S. A. Clayton, and A. F. A. Hoadley, "Lignite aided dewatering of digested sewage sludge," Water Research, vol. 43, no. 3, pp. 623-634, 2009.

[10] C. J. Miller, H. Mi, and N. Yesiller, "Experimental analysis of desiccation crack propagation in clay liners," Journal of the American Water Resources Association, vol. 34, no. 3, pp. 677686, 1998.

[11] N. Yesiller, C. J. Miller, G. Inci, and K. Yaldo, "Desiccation and cracking behavior of three compacted landfill liner soils," Engineering Geology, vol. 57, no. 1-2, pp. 105-121, 2000.

[12] Q. Xue, H. Lu, Y. Zhao, and L. Liu, “The metal ions release and microstructure of coal gangue corroded by acid-based chemical solution," Environmental Earth Sciences, vol. 71, no. 7, pp. 32353244, 2014.

[13] J.-W. Ding, Z.-S. Hong, and S.-Y. Liu, "Study of flow-solidification method and fluidity test of dredged clays," Rock and Soil Mechanics, vol. 32, supplement 1, pp. 280-284, 2011.

[14] S. S. Gao, Research on the Effect of Polypropylene Fiber on Mechanical Properties of Solidified Tideland Sludge, Zhejiang University, Hangzhou, China, 2012.
[15] Y.-X. Zhou and P.-Y. Yan, "Investigation on dry shrinkage and wet expansion of solidified saline soil containing different salts," Chinese Journal of Geotechnical Engineering, vol. 29, no. 11, pp. 1653-1658, 2007.

[16] H. Lu, Q. Zhang, Y. Dong, J. Li, and X. Zhang, “The adsorption capacity, pore structure, and thermal behavior of the modified clay containing SSA," Advances in Materials Science and Engineering, vol. 2016, Article ID 9894657, 7 pages, 2016.

[17] S. J. Gregg and K. S. Sing, Absorption, Surface Area and Porosity, Monographs of Academic Press, London, UK, 1982.

[18] K. W. Hu, D. Y. Jia, L. Yan et al., "Effect of natural zeolite and modified zeolite on adsorption of $\mathrm{Zn}^{2+}$," Soil and Fertilizer Sciences in China, no. 1, pp. 49-52, 2011.

[19] Y.-G. Fan, Y.-H. Li, and J.-B. Ma, "Mesoporous properties of porous crosslinked polystyrene absorbents," Chemical Journal of Chinese Universities, vol. 23, no. 8, pp. 1625-1626, 2002.

[20] J. H. Li, Q. G. Zhang, X. Sun, and B. Zhang, "Effect of bonding and void ratio on the mechanical behavior of structured soil," Journal of Tsinghua University (Science and Technology), vol. 48, no. 9, pp. 1431-1435, 2008.

[21] X. Qiang, L. Hai-jun, L. Zhen-ze, and L. Lei, "Cracking, water permeability and deformation of compacted clay liners improved by straw fiber," Engineering Geology, vol. 178, pp. 8290, 2014.

[22] D.-Y. Wang, C.-S. Tang, J. Li, B.-S. Liu, W. Tang, and K. Zhu, "Shear strength characteristics of fiber-reinforced unsaturated cohesive soils," Chinese Journal of Geotechnical Engineering, vol. 35, no. 10, pp. 1933-1940, 2013.

[23] Z.-M. Xu, Q. Xue, and Y. Zhao, "Research on time effect of modified sludge composites by triaxial tests on mechanical properties," Rock and Soil Mechanics, vol. 32, no. 6, pp. 1713-1717, 2011.

[24] CJJ 17-2004, Technical Code for Municipal Solid Waste Sanitary Landfill, China Architecture and Building Press, Beijng, China, 2004. 

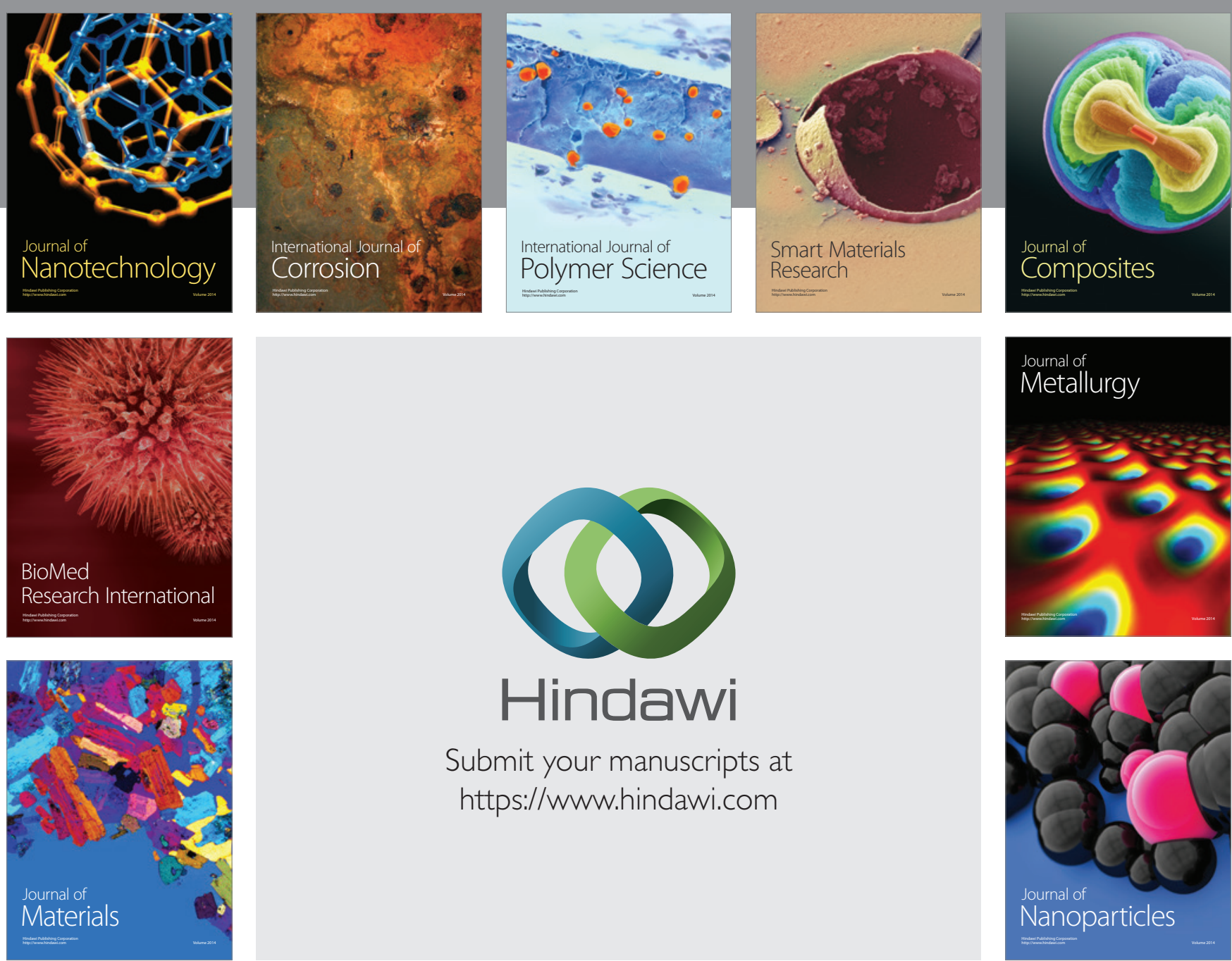

\section{Hindawi}

Submit your manuscripts at

https://www.hindawi.com

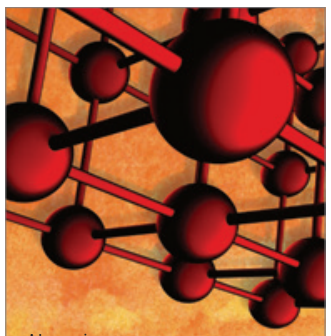

Materials Science and Engineering
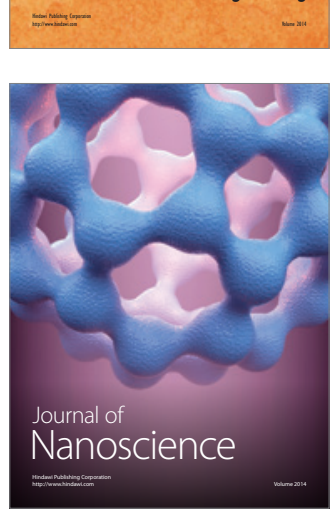
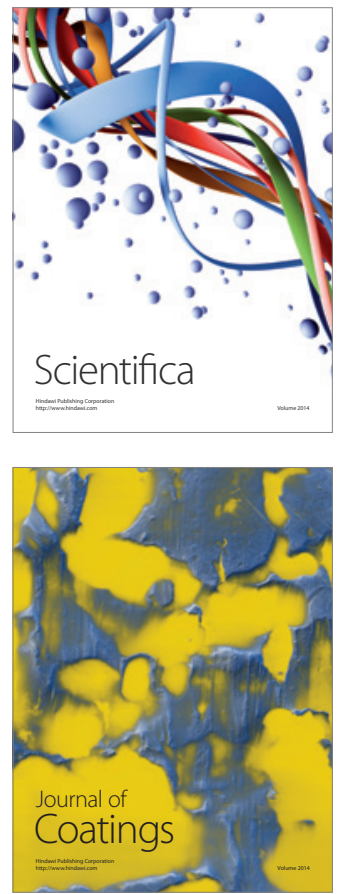
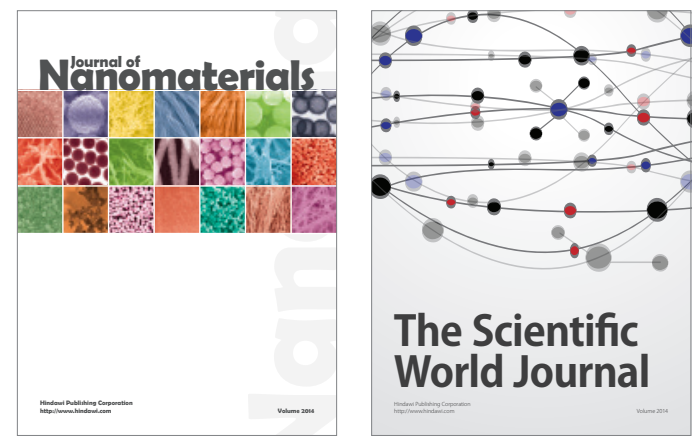

The Scientific World Journal
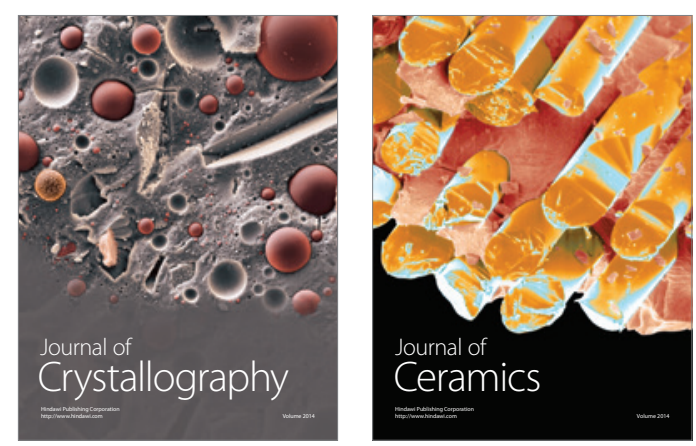
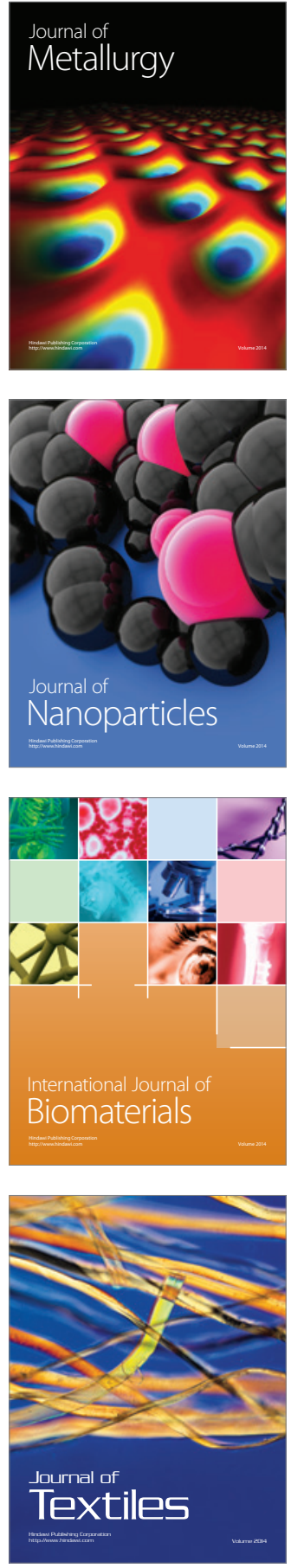